\title{
Outcome of chemotherapy for adult soft tissue sarcomas in Jos, north central Nigeria
}

\author{
Misauno M. A. ${ }^{1}$, Ode M.B. ${ }^{2}$, Shitta A.H. ${ }^{1}$, Nwadiaro H.C. ${ }^{3}$ \\ ${ }^{1}$ Department of Surgery, Jos University Teaching Hospital, P.M.B 2076, Plateau State Nigeria \\ ${ }^{2}$ Department of Orthopaedics and Traumatology, Jos University Teaching Hospital Jos, Plateau State Nigeria \\ ${ }^{3}$ College of Medicine University of Abuja Teaching Hospital Gwagwalada Nigeria
}

\section{Email address:}

micoyedim@yahoo.co.uk (Misauno M. A.)

\section{To cite this article:}

Misauno M. A., Ode M.B., Shitta A.H., Nwadiaro H.C.. Outcome of Chemotherapy for Adult Soft Tissue Sarcomas in Jos, North Central Nigeria. Journal of Cancer Treatment and Research. Vol. 2, No. 4, 2014, pp. 33-36. doi: 10.11648/j.jctr.20140204.11

\begin{abstract}
Background: Soft tissue sarcomas (STS) have a poor response to chemotherapy and reports have documented a $20 \%$ response rate. Chemotherapeutic regimens have evolved from the use of multiple drug combinations which were thought to be more efficacious, to high doses of single agent chemotherapy and targeted therapies. Predicting the response to chemotherapy in soft tissue sarcomas is difficult because even tumours of the same class exhibit different patterns of responsiveness to the same drugs. Single agent Adriamycin chemotherapy for soft tissue sarcomas is cheap and reputably gives comparable treatment outcomes to combination therapies. This study was therefore aimed at determining the outcome of management of soft tissue sarcomas with single agent Adriamycin chemotherapy. Patients and Method: This was a prospective analysis of consecutive patients managed for STS with single agent Adriamycin at the Jos University Teaching Hospital from January 2000 to December 2009.Results: A total of 89 adult soft tissue sarcomas were managed in 49 males and 40 females $(\mathrm{M}: \mathrm{F}=1.2: 1)$. The mean age of the study population was $37.4+/-12.6$ with age range of 18 to 85years.Forty patients (44.9\%) could afford chemotherapy with single agent Adriamycin and formed the basis of this study while $49(53.1 \%)$ could not afford chemotherapy. All the tumours were more than $5 \mathrm{~cm}$ in size at presentation. Rhabdomyosarcoma was seen in 17 patients (42.5\%), fibrosarcoma in 14 (35\%), liposarcoma and dermatofibrosarcoma 4 $(10 \%)$ each and one patient $(2.5 \%)$ had synovial sarcoma. Response to chemotherapy was seen in seven patients $(17.5 \%)$ and this was noticed within six weeks of chemotherapy. Conclusion: Response to chemotherapy with single agent Adriamycin for the treatment of soft tissue sarcomas is very poor and it is difficult to predict which patient will respond to this therapy in our setting. We therefore suggest that all patients with STS on single agent Adriamycin in resource scarce settings should have their treatment discontinued or changed to other chemotherapeutic combinations if there is no response to chemotherapy after six weeks.
\end{abstract}

Keywords: Single Agent Adriamycin, Soft Tissue Sarcomas, Outcome

\section{Introduction}

Generally speaking, soft tissue sarcomas (STS) have a poor response to chemotherapy and several reports have documented a $20 \%$ response rate.(1-2) The management of STS in resource scarce settings is fraught with so many challenges ranging from late presentation, difficulty in ascertaining the correct pathologic diagnosis(3) and inadequate access to appropriate treatment.(4-6) In these resource scarce settings, emphasis on prevention and treatment of infectious diseases like HIV/AIDS and malaria take up a major part of the national health budget and little or no attention is paid to cancer management. This implies that the patients with cancers are left to fend for themselves and this may contribute to the late presentation that we typically see.(7)

Late presentation in STS connotes a locally advanced or metastatic disease that is largely treated with regional or systemic chemotherapy.(8-9)This mode of presentation is very common in our setting and surgery which is cheap and readily available cannot achieve cure. This leaves us with chemotherapy with different drug combinations as the only reliable treatment option. These chemotherapeutic regimens have evolved over time from the use of multiple drug combinations which were thought to be more efficacious (notable among which are 
Ifosfamide+Cyclophosphamide and Etoposide), to high doses of single agent chemotherapy and even targeted therapies.(10-13)All these treatment options are very expensive and are associated with considerable toxicities warranting a careful selection of patients that should receive them. These tend to limit the dose of the drugs used and influence the different drug combinations.(14) Several studies have compared the efficacy of single agent adriamycin and other combination chemotherapies and have shown that adriamycin can be used as a single agent therapy in STS.(15-17)This Adriamycin is relatively cheap and available in our practice with tolerable side effects. It however requires periodic cardiac assessment during therapy to prevent cardio toxicity.

Predicting the response to chemotherapy in soft tissue sarcomas is difficult because even tumours of the same class exhibit different patterns of responsiveness to the same drugs. To reduce this difficulty, genomic profiling and molecular evaluation techniques have been used to differentiate the tumour types(18-19) while efforts are being made to assess their response to chemotherapy through advanced pathologic tests like the Ki-67 which is a cellular marker of somatic cell proliferation, cluster of differentiation 100 (CD100) that is useful for assessing the angiogenesis potential of the tumour and assay for the presence of multi-drug resistance proteins in some adult rhabdomyosarcomas.(20-22). The implication of these advancements is that if we could pre determine which patient will not respond to a particular type of chemotherapy, there will be no need to expose him to the toxic effects of such drugs. We will therefore rather treat him based on the pharmacogenomics of his tumour; this approach is referred to as personalized cancer therapy.(23-24)

These immunohistochemical techniques are not available in our practice and oral discussions with our pathologists suggest a $50 \%$ discordance in pathology reporting for soft tissue sarcomas compared with $26 \%$ reported by Shiraki et al.(25) This scenario makes it difficult to tell which patient with STS in our practice will benefit from neoadjuvant cytotoxic chemotherapy.

This study was therefore aimed at evaluating our experience with single agent Adriamycin chemotherapy in a resource scarce setting.

\section{Patients and Method}

This was a prospective analysis of consecutive patients managed for STS with single agent Adriamycin at the Jos University Teaching Hospital from January 2000 to December 2009.

Non consenting patients and those that were lost to follow up were excluded from the study.

\section{Method}

After obtaining an informed consent, consecutive patients with soft tissue sarcomas were assessed clinically, radiologically and pathologically with the aim of staging the tumour and deciding on its suitability for neo-adjuvant chemotherapy. Clinical measurements of the tumour coupled with laboratory and radiologic monitoring of metastatic lesions were done before commencement of chemotherapy and repeated as is necessary at 3 weeks (before next chemotherapy) and six weeks.

Chemoresponsiveness was defined as clinical reduction in maximum tumour diameter as measured from a reproducible point by $10 \%$ or more or complete regression of metastatic deposits at 3 weeks or 6 weeks after chemotherapy. Chemotherapy was stopped after two cycles in patients that showed no evidence of response or in whom the tumour progressed despite the chemotherapy.

Data was obtained on patient demographics, tumour location, histopathologic diagnosis, number of cycles of chemotherapy received and chemoresponsiveness. This data was analysed using Epi-info version 3.5.2 for means and standard deviations.

\section{Results}

A total of 89 adult soft tissue sarcomas were managed in 49 males and 40 females (M: $F=1.2: 1)$. The mean age of the study population was $37.4+/-12.6$ with age range of 18 to 85years. Only forty patients $(44.9 \%)$ could afford chemotherapy with single agent Adriamycin and formed the basis of this study while the remaining 49 (53.1\%) did not have chemotherapy because they could not afford it.The mean tumour size was $7 \mathrm{~cm}+/-1.7$ cm.Rhabdomyosarcoma was seen in 17 patients (42.5\%), fibrosarcoma in 14 (35\%),liposarcoma and dermatofibrosarcoma accounted for $4(10 \%)$ each and one patient $(2.5 \%)$ had synovial sarcoma. See table 1 .

Table 1. Shows Types of soft tissue sarcomas and the distribution of response to Adriamycin.

\begin{tabular}{lll}
\hline Type of soft tissue sarcoma & Number & $\begin{array}{l}\text { Distribution of responders to } \\
\text { Adriamycin }\end{array}$ \\
\hline Rhabdomyosarcoma & 17 & 4 \\
Fibrosarcoma & 14 & 2 \\
Liposarcoma & 4 & 0 \\
Dermatofibrosarcoma & 4 & 0 \\
Synovial sarcoma & 1 & 1 \\
Total & 40 & 7 \\
\hline
\end{tabular}

There was demonstrable clinical response to chemotherapy in $7(17.5 \%)$ of the patients that had chemotherapy whereas the remaining 33 patients $(82.5 \%)$ did not show any clinical response to chemotherapy. Six patients responded to the chemotherapy within three weeks of administration while one patient responded after four weeks.All responders were aged forty years and under with well differentiated tumours

The histopathology and location of the chemoresponsive tumours were as follows; 3 patients had alveolar rhabdomyosarcoma of the thighs, 2 had fibrosarcomas of the anterior abdominal wall, 1 patient had a retroperitoneal 
pleomorphic rhabdomyosarcoma and 1 had synovial sarcoma of the left knee. (FIG 1)

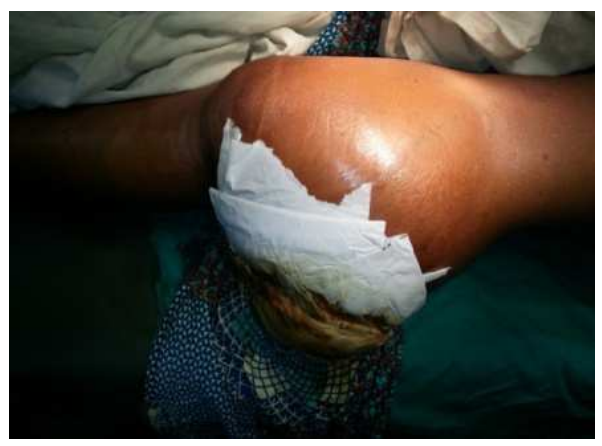

Fig. 1. Synovial sarcoma of the left knee.

\section{Discussion}

The main finding of this study was that only $17.5 \%$ responded to Adriamycin and this response was noticed within four to six weeks of administration in all the responders. This response rate is low compared to the 20 to $50 \%$ reported by Shinohara et al. This disparity can be explained by our small patient population in addition to the fact that we evaluated gross clinical response rather than the more sensitive radiological assessment using CT scan or MRI which were not available to us at the time of this study. That all the tumours in this study were more than $5 \mathrm{~cm}$ in size may explain the low response rate since tumours of this size are associated with a poor prognosis as has been reported by Changchien et al.(26)

All patients that responded to chemotherapy in this study were below forty years old and had low grade tumours in agreement with reports from other researchers. $(2,25,27)$

This study also revealed that rhabdomyosarcoma was the most common soft tissue sarcoma in our practice and is in agreement with what Mandong et al reported from the same institution seven years earlier.(28)Even though rhabdomyosarcomas were the most chemo-responsive cancers in this study, only four responded to treatment out of 17 and three out of these responders had alveolar rhabdomyosarcomas. It is also curious to note that out of the nine alveolar rhabdomyosarcomas in this study, only three responded to chemotherapy. This observation tended to imply that it is difficult to predict which soft tissue sarcoma will respond to chemotherapy.

\section{Conclusion}

Response to chemotherapy with single agent Adriamycin for the treatment of soft tissue sarcomas is very poor and it is difficult to predict which patient will respond to this therapy in our setting. We therefore suggest that all patients with STS on single agent Adriamycin in resource scarce settings should have their treatment discontinued or changed to other chemotherapeutic combinations if there is no response to chemotherapy after six weeks.

\section{References}

[1] Mouridsen HT, Bastholt L, Somers R, Santoro A, Bramwell $\mathrm{V}$, Mulder $\mathrm{JH}$, et al. Adriamycin versus epirubicin in advanced soft tissue sarcomas. A randomized phase II/phase III study of the EORTC Soft Tissue and Bone Sarcoma Group. Eur J Cancer Clin Oncol. 1987 Oct;23(10):1477-83.

[2] Shinohara N, Yokoyama K. [Adjuvant chemotherapy of soft tissue sarcoma]. Gan To Kagaku Ryoho. 1990 Feb;17(2):198-204.

[3] African Pathologists' Summit Working G. Proceedings of the African Pathologists Summit; March 22-23, 2013; Dakar, Senegal: A Summary. Arch Pathol Lab Med. 2014 Jun 25.

[4] Eyesan SU, Obalum DC, Nnodu OE, Abdulkareem FB, Ladejobi AO. Challenges in the diagnosis and management of musculoskeletal tumours in Nigeria. Int Orthop. 2009 Feb;33(1):211-3.

[5] Fatusi OA, Ajike SO, Olateju SO, Adebayo AT, Gbolahan OO, Ogunmuyiwa SA. Clinico-epidemiological analysis of orofacial rhabdomyosarcoma in a Nigerian population. Int $\mathrm{J}$ Oral Maxillofac Surg. 2009 Mar;38(3):256-60.

[6] Chukwuanukwu TO, Anyanwu SN. Giant fibrosarcoma prostuberans of abodominal wall: management problems in resources-constrained country. Niger J Clin Pract. 2009 Sep;12(3):338-40.

[7] Stefan DC, Elzawawy AM, Khaled HM, Ntaganda F, Asiimwe A, Addai BW, et al. Developing cancer control plans in Africa: examples from five countries. Lancet Oncol. 2013 Apr;14(4):e189-95.

[8] Pfeffer MR, Sulkes A, Biran S. Treatment of advanced soft tissue sarcomas with a modified CYVADIC protocol. Oncology. 1984;41(5):308-13.

[9] Roseman JM. Effective management of extremity cancers using cisplatin and etoposide in isolated limb perfusions. $\mathrm{J}$ Surg Oncol. 1987 Jul;35(3):170-2.

[10] Borden EC, Amato DA, Edmonson JH, Ritch PS, Shiraki M. Randomized comparison of doxorubicin and vindesine to doxorubicin for patients with metastatic soft-tissue sarcomas. Cancer. 1990 Sep 1;66(5):862-7.

[11] Eggermont AM, Schraffordt Koops H, Lienard D, Kroon $\mathrm{BB}$, van Geel $\mathrm{AN}$, Hoekstra $\mathrm{HJ}$, et al. Isolated limb perfusion with high-dose tumor necrosis factor-alpha in combination with interferon-gamma and melphalan for nonresectable extremity soft tissue sarcomas: a multicenter trial. J Clin Oncol. 1996 Oct;14(10):2653-65.

[12] Wilky BA, Meyer CF, Trent JC. Pazopanib in sarcomas: expanding the PALETTE. Curr Opin Oncol. 2013 Jul;25(4):373-8.

[13] Edmonson JH, Ryan LM, Blum RH, Brooks JS, Shiraki M, Frytak S, et al. Randomized comparison of doxorubicin alone versus ifosfamide plus doxorubicin or mitomycin, doxorubicin, and cisplatin against advanced soft tissue sarcomas. J Clin Oncol. 1993 Jul;11(7):1269-75.

[14] Budd GT. Palliative chemotherapy of adult soft tissue sarcomas. Semin Oncol. 1995 Apr;22(2 Suppl 3):30-4. 
[15] Rouesse J, Spielmann M, Le Chevalier T, Tubiana-Hulin M, Tursz T. [Chemotherapy of soft tissue sarcoma in adults]. Bull Acad Natl Med. 1991 Nov;175(8):1251-9; discussion 9-60.

[16] Bramwell VH. Current perspectives in the management of soft-tissue sarcoma. The role of chemotherapy in multimodality therapy. Can J Surg. 1988 Nov;31(6):390-6.

[17] Bramwell VH, Anderson D, Charette ML. Doxorubicinbased chemotherapy for the palliative treatment of adult patients with locally advanced or metastatic soft-tissue sarcoma: a meta-analysis and clinical practice guideline. Sarcoma. 2000;4(3):103-1

[18] Conley AP, Trent J, Zhang W. Recent progress in the genomics of soft tissue sarcomas. Curr Opin Oncol. 2008 Jul;20(4):395-9.

[19] Clarkson P, Ferguson PC. Primary multidisciplinary management of extremity soft tissue sarcomas. Curr Treat Options Oncol. 2004 Dec;5(6):451-62.

[20] Dziegiel P, Salwa-Zurawska W, Zurawski J, Wojnar A, Zabel M. Prognostic significance of augmented metallothionein (MT) expression correlated with Ki-67 antigen expression in selected soft tissue sarcomas. Histol Histopathol. 2005 Jan;20(1):83-9.

[21] Campos M, SG DEC, Ribeiro GG, Eguchi FC, Silva SR, CZ $\mathrm{DEO}$, et al. Ki-67 and CD100 immunohistochemical expression is associated with local recurrence and poor prognosis in soft tissue sarcomas, respectively. Oncol Lett. 2013 May;5(5):1527-35.
[22] Komdeur R, Klunder J, van der Graaf WT, van den Berg E, de Bont ES, Hoekstra HJ, et al. Multidrug resistance proteins in rhabdomyosarcomas: comparison between children and adults. Cancer. 2003 Apr 15;97(8):1999-2005.

[23] Stebbing J. Cancer: Where were we, where are we, where are we going. Med Leg J. 2014 Jun 9;82(2):57-66.

[24] Michielin O, Coukos G. [Genomics medicine and oncology]. Praxis (Bern 1994). 2014 May 7;103(10):591-6.

[25] Shiraki M, Enterline HT, Brooks JJ, Cooper NS, Hirschl S, Roth JA, et al. Pathologic analysis of advanced adult soft tissue sarcomas, bone sarcomas, and mesotheliomas. The Eastern Cooperative Oncology Group (ECOG) experience. Cancer. 1989 Jul 15;64(2):484-90.

[26] Changchien YC, Tatrai P, Papp G, Sapi J, Fonyad L, Szendroi M, et al. Poorly differentiated synovial sarcoma is associated with high expression of enhancer of zeste homologue 2 (EZH2). J Transl Med. 2012;10:216.

[27] Ogilvie CM, Crawford EA, Slotcavage RL, King JJ, Lackman RD, Hartner L, et al. Treatment of adult rhabdomyosarcoma. Am J Clin Oncol. 2010 Apr;33(2):12831.

[28] Mandong BM, Kidmas AT, Manasseh AN, Echejoh GO, Tanko MN, Madaki AJ. Epidemiology of soft tissue sarcomas in Jos, North Central Nigeria. Niger J Med. 2007 Jul-Sep;16(3):246-9. 